\title{
Web Technologies and Sciences Epistemologies
}

\author{
Antonio Cartelli \\ University of Cassino, Cassino (FR), Italy
}

cartan@officine.it

\begin{abstract}
The paper reports first of all the results of several studies on misconceptions and mental schemes many researchers carried out in different disciplines and several countries. At the end of this section an overview of open questions and unresolved problems concerning knowledge construction is reported. The paper continues describing the different ways computers entered in education and how they were used to help students in overcoming their difficulties. At last a snapshot of the influence of the Internet phenomenon on the educational processes follows. The last sections propose the analysis of two experiences the author made up with the use of Web technologies and suggest the adoption of an Information system to hit the following target: to improve the everyday work of teachers, to help students in overcoming their wrong ideas, to deepen the analysis of students' ideas and attitudes when they approach scientific disciplines and to redefine the relations existing among the disciplines involved in the study of teaching/learning processes.
\end{abstract}

Keywords: misconceptions, mental schemes, meaningful learning, Web technologies, database, knowledge monitoring

\section{Introduction}

"Didactics is a science having its roots in distant times" asserts L. Santelli Beccegato (Santelli Beccegato, 1998). Main aims of this discipline, says the author, are the interpretation and the design of teaching work, so that the optimization of educational processes and the best qualitative and quantitative results can be reached. During last decades many scientific paradigms intervened to support Didactics in interpreting and modifying teaching/learning processes and, as a result, the adoption of strategies strongly based on communication technologies was proposed. A key role was played in this context by multimedia and hypermedia and particularly by computers and networks.

A lot of studies concerning the errors students made while approaching scientific disciplines took place from concrete teaching experiences beginning from early '70s. As a result of the these researches the terms preconceptions, misconceptions and mental schemes were introduced to describe different situations marked by the presence of wrong ideas. Following Driver and Erickson definitions (Driver, 1983) the terms 'preconceptions' and 'misconceptions' are better used to describe wrong ideas people show when they meet scientific concepts for the first time or when they're involved in the study of a new discipline (in such a case they are usually called beginners). The terms 'mental schemes' have to be used, on the con-

Material published as part of these proceedings, either on-line or in print, is copyrighted by Informing Science. Permission to make digital or paper copy of part or all of these works for personal or classroom use is granted without fee provided that the copies are not made or distributed for profit or commercial advantage AND that copies 1) bear this notice in full and 2) give the full citation on the first page. It is permissible to abstract these works so long as credit is given. To copy in all other cases or to republish or to post on a server or to redistribute to lists requires specific permission from the publisher atpublisher@intormingscience.org trary, when people's personal hypotheses in phenomena explanations can be attributed to well organised sets of ideas. These personal frames, always conflicting with scientific paradigms and disciplines' structure, are usually called 'natural mental schemes'.

In what follows the above terms will be used to describe the presence of "wrong ideas" in students' 
Web Technologies and Sciences Epistemologies

minds and more generally in people's hypotheses with no reference to their origin and to the differences existing among them.

It is surely beyond the aim of this paper the detailed discussion of all wrong ideas and of the great amount of studies until now made on them, but in the author opinion it is very important to make an attempt to answer to the following questions - What (are there specific fields of human knowledge evidencing wrong ideas or not)? - Where (is there a region, a country or a continent where differences with respect to other places all over the world can be detected)? - When (are there particular ages marked by the presence of wrong ideas)? - Why (are there one or more specific reasons for the existence of wrong ideas)? - Can we overcome them (are there strategies that prove helpful in helping people to overcome their difficulties and to easily gain the correct scientific concepts)?

The above questions create a different reference frame within which to analyse multimedia and hypermedia influence on teaching practice and state the need for an answer to the following questions: a) is there the need for a more efficient monitoring of learning processes? b) can IT help in monitoring teaching/learning processes? c) what relationship is there between Didactics and IT? c) what role the teachers have to play in this context? etc. In the last sections of this paper some answer to the above questions will be given and further hypotheses will be discussed.

\section{Preconceptions, Misconceptions and Mental Schemes: A Survey}

First researches on concept construction and mental schemes have to be attributed to Piaget (Piaget 1950, Piaget 1973) who studied space, time and causality concepts in the context of individual mental development to obtain information on history of science. Many further studies reverted Piaget perspective and analyzed history of science to find information on students' wrong ideas.

The author's twenty years experience as a teacher with differently aged students and his study of their wrong ideas in various scientific fields brought to the discovery of many misconceptions in Physics, Computer Science and Statistics (Cartelli 1985, Cartelli 1994, Cartelli 1997, Cartelli 2000) and led to the hypothesis of specific mental schemes opposing to the correct learning of scientific concepts. These results found a confirmation in the researches held by other scholars all over the world and induced the author to study the influence of cultural, anthropological and disciplinary factors in misconceptions and mental schemes presence and distribution all over human knowledge.

The MLRG (Meaningful Learning Research Group) Web site (MLRG, 2002) revealed a good source of information on wrong ideas and meaningful learning. The proceedings of four international conferences concerning the above topics are in fact collected in this site.

Very likely the themes reported in the following sections will not exhaust all the topics scholar and researchers discussed in those seminars but they will undoubtedly contribute in expanding the focus on the problem of wrong ideas and knowledge construction.

\section{What Misconceptions Were Detected?}

While reading the proceedings of the conferences reported in MLGR site the evidence for wrong ideas all over the scientific fields of human knowledge emerges also if misconceptions are not equally distributed among the various disciplines. Physics reports till now the highest number of researches on misconceptions and the highest number of investigated topics. Kinematics, dynamics and specifically speed, acceleration, trajectory motion, force and motion, vector fields, mathematical models of phenomena, free fall, momentum, Newton's action-reaction principle, distance action, weight and gravity, air pressure, water pressure, flotation, buoyancy, energy and field concepts are, perhaps, the more and better studied topics, 
where both misconceptions and mental schemes have been revealed; some studies concerning the above topics (Cartelli 1985, Vicentini 1998) involved middle and high school students together with university students. The above topics aren't the only ones interested by misconceptions' presence, there are in fact: diffusion and osmosis, conservation of matter, liquid quantity and liquid volume, heat and temperature, linear and solid expansion, kinetic particle model, kinetic molecular theory, state aggregations of matter, thermodynamics, sound and its propagation, geometrical optics, light and its properties, electricity, electric circuits, electrostatics and electrodynamics, magnetism, atomic conceptions, nuclear physics, waveparticle duality, special relativity etc.

The studies devoted to the discovery of misconceptions in Mathematics concerned the following topics: elementary geometry, parallel lines, equal and equivalent figures, geometric problem solving, fractions, algebra, powers and radicals, computational expertise, problem solving, theorem proving, theorems' necessary and sufficient conditions, cause-effect relationships. Other misconceptions have been revealed in studies on differentiation, derivatives and their interpretation but there are also researches evidencing misconceptions in the use of isometries and vector spaces. While remaining in the mathematical field misconceptions concerning statistics and probability have to be noted: wrong ideas have been detected in fact on the mean value of a set of numerical data, on other statistical parameters and on the use of distributions (Cartelli, 2001).

Also astronomy and earth sciences have been affected by misconceptions' presence: in the first case wrong ideas interested lunar phases, equinoxes, space sciences, origin of earth and moon, in the second case they appeared in plate tectonics and earthquakes. Some misconceptions have been noted also in cosmogony theories.

One can think the above topics have a major "confusing effect" on students' minds because of the rules and equations the corresponding disciplines adopt (i.e. their mathematical representation of reality), against other disciplines like Biology, Chemistry etc., but it is wrong. Many studies report in fact the presence of misconceptions in Biology, Chemistry, Chromatography, Biochemistry, Stoichiometry, Genetics etc.

As an example some topics interested by misconceptions' presence in Biology follow: animals' classification, Mendelian genetics, structure-function correlation in creatures, natural selection Vs adjustment evolution, photosynthesis (light and dark reactions), cellular respiration, ecology toxicity, health and nutrition. In Chemistry the analysis of misconceptions has interested general concepts like atom and molar weight, notations and element classification, but also more specific topics concerning solutions, energy exchanges in chemical reactions, chemical equilibrium, volume conservation in solutions and reactions, acid-base chemistry and matter.

At last it has to be pointed out the case of Computer Science where misconceptions pertaining computer programming, computer structure, networking etc. have been detected (Cartelli 1994, Cartelli 1997, Lemut 1993). In the author opinion the case of CS is a very special case with respect to the above ones. More than other disciplines, in fact, CS has less if not at all reference with natural phenomena (how can then be explained the hypothesis that assigns a great relevance to sensorial perception in the determination of wrong ideas or vice versa?).

At the end of this survey it is important to signal the presence of wrong ideas in other fields of human knowledge like history, geography and literature.

\section{Where Misconceptions Were Found?}

In the MLRG Web site are reported researches on wrong ideas from many different countries, without any distinction among North, South, East and West (i.e. Botswana, Brazil, Caribbean Isles, China, Costa Rica, 
Web Technologies and Sciences Epistemologies

Great Britain, Finland, India, Israel, Italy, Korea, Norway, Slovenia, Spain, Taiwan, USA, Venezuela are some of the countries interested by the above studies).

It has to be noted that only in a few cases the same topics have been analysed in almost all countries and that mathematics, general sciences, environmental chemistry and thermal phenomena were in that cases the topics under observation.

Furthermore it has to be noted that the monitoring of the studies on misconceptions is very difficult because of two different factors: 1) regionalism (i.e. many countries periodically house meetings where only local teachers and scholars gather and share their experiences); 2) discipline segregation (i. e. many researches on students' difficulties often fall in single discipline's domain and the results of these studies are published in the proceedings of that particular discipline). In both cases the results of the researches can be very difficult to retrieve.

A constant parameter seems to characterise the presence of wrong ideas across the various topics: if it is true that misconceptions can be detected all over the world with no regard to longitude or latitude, only less effects can be attributed to local cultural aspects (i.e. in different regions there are only little differences among the various kinds of wrong ideas pertaining to the same concepts, or among the different reasons for a wrong explanation).

\section{When Misconceptions Were Revealed?}

The researches on preconceptions, misconceptions and mental schemes involve differently aged people: from pupils, to middle school, high school and university students and sometimes extend to other people like workers or professionals. It has to be noted that only in very rare cases some specific topics have been analysed across the differently aged groups of students.

First of all there are two different approaches the above studies can adopt. A first set of researches analyses pupils reasoning and more generally the ideas people show when they explain different phenomena, without any correlation among their explanations and the scientific knowledge, i.e. they only evaluate the internal coherence of that set of concepts; Driver and Erickson (Driver, 1983) call ideographic or naturalistic these studies. Other researches involve people who had already approached scientific topics (or were beginners) and evaluate the correctness of their ideas with respect to the scientifically accepted ones; Driver and Erickson (Driver 1983) call them nomothetic studies.

The author's experience (falling in the nomothetic tradition) with middle and high school students ideas on physical and statistical phenomena and the answers university students gave to specific tests concerning the same topics, show there is no or less difference between the wrong ideas evidenced by the various students' samples. Differences have only to be noted in the number of students within each sample: while $70-80 \%$ of middle school students is 'affected' by wrong ideas, 50-60\% of high school students manifest the same errors and only $30-40 \%$ of university students show them in their answers.

A suggestion emerging from great part of the studies on students' wrong ideas reported in MLRG international seminars is the reduction of the number of individuals showing wrong ideas when specific teaching strategies are applied. This result agree with the author's ones also if there is no systematic research evidencing the outcome of the application of specific teaching strategies to a given set of students during their whole school life from early school to university.

\section{Why Are There Misconceptions?}

The answer to the above question can be very complex and articulated (if we extend our considerations to philosophical argumentation), but we'll limit in this paper to report some of the most common and accepted theories on the construction of concepts and knowledge. 
Piaget (Piaget 1950, Piaget 1973) proposed the theory of genetic epistemology to explain the birth and the development of fundamental concepts like space, time, causality, conservation etc. He hypothesised a parallelism among the psychological development of individual learning processes and the historicalsocial evolution of the above concepts. Also if Piaget's ideas were very important for a great amount of further researches they received many criticisms from different authors; recent works, for example, reverse the perspective under which Piaget looked at his parallelism and proposed the study of history of science to interpret students' thinking.

Ausubel (1990), with respect to Piaget, studied the way pre-existing knowledge can affect learning processes and proposed a meaningful learning and a mechanical learning as the two basic models of learning. Ausubel identified also some primary ideas leading to meaningful learning and called them subsumers. Subsequent studies showed that also if the students have the right subsumers to arrive to a meaningful learning they can reject them and can give rise to misconceptions in their knowledge (West, 1974).

Starting from the results of first cognitive psychologists other researchers proposed a constructivistic theory for the interpretation of learning phenomenon and knowledge construction. The main tenets of last constructivistic ideas can be summarised as follows (Greening 2000, Varisco 2002):

- meaning is not transmitted (learning occurs as a process of adjustment of existing concepts)

- understanding is based on interaction among a complex weave of factors (i.e. the learner's goals and existing concepts, the content of the learning experience, the context in which the learning takes place, etc.)

- puzzlement motivates learning (the sense of dissatisfaction emerges from experiences that threaten existing conceptual structures)

- social negotiation and viability are the principle forces involved in the evolution and construction of knowledge.

This new perspective implied radical changes in carrying out educational processes and strongly involved IT use for managing learning construction.

Recently many scholars introduced the "novice Vs expert paradigm" to explain wrong ideas as they appear in a specific scientific field, including CS (i.e. wrong ideas are only expressed by people having not yet reached the expert status). This simple paradigm has only a gap: it doesn't explain the presence of mistakes in people's answers to specific questions when they have to be considered skilled or after they have attended many years of study. It poses also the problem of the meaning of the word expert and of teaching effects (and meaning).

\section{What can be done to Help People in overcoming their Misconceptions?}

During last decades many different strategies were proposed and experimented at different extents to help people in overcoming the difficulties they met while building their scientifically correct mental schemes.

Great part of these recovery interventions were devoted to the design of specific teaching processes to be adopted in the classrooms but sometimes also teachers were involved in these experiences (when studies on misconceptions were addressed to the same teachers).

As it is reported in MLRG international seminars the basic strategies many researchers found useful were: a) the use of concept maps and graphs in phenomena description, b) the use of meta-cognitive strategies, c) computer use in teaching-learning situations (a detailed description of their use will appear in the next section), d) the use of constructivistic strategies in everyday teaching work, e) the introduction of philosophy of science elements in everyday teaching work. 


\section{Conclusions}

In the author opinion the studies on wrong ideas are important not only because they lead to new teaching strategies but also because they put many other questions: is scientific knowledge a particular and deep natural knowledge or it is something different? Among the various disciplines can we recognise unique knowledge methods or have to be supposed different methods for different disciplines if not for different branches within them? Are scientific knowledge structures resistant to time (i.e. after having built a scientifically correct mental frame a student will always use it)? Are the students ever the same (i. e. new students generations live in very reach environments that are very different from the ones within which their teachers grew up, how these environments will interact with students' knowledge strategies)?

\section{IT and Education: A Survey}

Computers entered in education very early in their history, often under the influence of different pedagogical and psychological theories. Nonetheless the way IT influenced educational processes, curricula development and everyday teaching followed very closely computer evolution in any other human operation. It is well known in fact the history of last thirty years of computing can be split into the following periods: the '70s when computers were mostly used for calculus, the '80s when first PCs appeared and personal computing transformed centralized IT in distributed IT while GUI and information management become more important than calculus, the '90s when networking, distributed computing and CMC (Computer Mediated Communication) settled the transformation of computers from elaboration instruments into communication media.

With respect to the learning problems reported in the above section two points of view can be identified to describe the intervention of computers in education: a former one we will call bottom-up that assigns to computing the task of supporting specific teaching situations or at least disciplinary teaching situations; a latter one we will call top-down where IT and computing are directly involved in planning and design of information systems and learning environments fully or partially based on psychological and pedagogical theories.

The above hypotheses have nothing in common with R. Taylor metaphors (Taylor, 1980); he gave, in fact, an interesting classification of the ways computer could be used in education and proposed the following terms for the metaphors of computer use: tutor, tool and tutee. L. Galliani (1999) extended the meaning of these terms so that tutor appellation describes now a computer system supporting or substituting (in the specific situation of auto-instruction) teachers and tutors in their work. Examples for this kind of systems are software packages like CAI (Computer Assisted Instruction) or CAL (Computer Assisted Learning). CAI tools have the main property they implement into the subjects to be taught the structure of the software the designer made up, they therefore force the users to follow a well defined route within them. Examples for this kind of software are the following ones: 1) packages devoted to theorems' demonstration or physical phenomena emulation and tools giving the users no or less autonomy in their analysis and studying of phenomena; 2) testing/assessment software containing questions with pre-built multiple answers or yes/no answers, where the difficulty level of the questions can be either predefined by the teacher, or determined by the answers the students give to former questions, or autonomously selected by students themselves. These tools can also have feed-back functions guiding the students to their correct answers or can assign specific scores to the skills they gain while using them, under the guidelines of F. Skinner's planned education (Skinner, 1960) (Skinner is one of the most representative scholars of behaviouristic psycho-pedagogical theory and assigns a great relevance to the structure, to the order and to the times of the subjects to be taught because gives a great relevance to the use of the stimulus-answerreinforcement sequence for the achievement of a personal teaching). CAL software packages differ from CAI tools because they give more importance to learning than to teaching. In these packages, with respect to the former ones, users can freely move within different scenarios; they can decide by themselves what 
to do or can browse in a personal way the context the software proposes. A good example for these software packages is given by educational games and edutainment tools (this last term is an acronym for education-entertainment). Further examples for CAL software are the simulation systems (often used for training) and many multimedia or hypermedia tools one can use for examining large amount of data, or for exploring and browsing specific contexts; these last products are often provided by co-authoring functions (i. e. text processing functions).

Taylor used the term tool to describe the software students could use to produce and manage information (i.e. editors, word processors and more generally office automation tools), and adopted the term tutee to describe the use of software tools for the creation of specific development environments (like the ones Papert created with LOGO).

After Taylor's metaphors many other software tools falling in his classification were developed, but there were also packages that didn't belong to those categories. As an example we remember here two results of Artificial Intelligence application in education: ICAI Systems (Intelligent Computer Assisted Instruction Systems) and ITS (Intelligent Tutoring Systems). In these systems with respect to CAI and CAL tools there is no pre-determined teaching route or strategy but there are three independent modules interacting among themselves: an expert (i.e. a knowledge basis on a very specific domain), a pupil (including the knowledge representation of a student interacting with the system) and a teacher (implementing the teacher behaviour rules of everyday teaching and determining the didactic strategies to be adopted during the student-system dialogue).

The Internet, its development and its influence on education are further phenomena that don't find a specific place in Taylor's metaphors. The relationship between the Internet and education can be seen from two different points of view: the former one concerns the influence of the new medium on knowledge structure and construction, the latter one refers to the different ways this medium can be used in educational contexts. On the first hand we find the virtual communities proposed by Rheingold (Rheingold, 1994) (groups of individuals that use the Net exclusively for their interpersonal communication so expanding the meaning of community), or the Lévy (1996) idea of joint or collective intelligence (strongly dependent on the increase of the interpersonal communication speed and on the great amount of information the Net makes available). Calvani (Calvani 1999, Calvani 2000) at last, while collecting hypotheses from many other scholars, states today knowledge is no more only linear, sequential, closed, hierarchical, but it is also hypertextual and multimedial. Calvani reports also that the Net extends the social negotiation aspects of knowledge and contributes in its distributed character; in this way he asserts the Internet supports the construction of a meaningful knowledge. On the second hand the Internet inherits and strengthens the results of previous distance education experiments and proposes new costructivistic experiences: in this perspective have to be interpreted recent studies extending the ones on learning apprenticeship (Casey, 1996), or the experiences on cooperative and collaborative learning (Johnson 1985, Jonassen 1994, Jonassen 1994, Mc Lellan 1996) and Web based training experiments.

The conclusion we can draw gives to computers and IT a relevant role in education because of the better results one can have while adopting them but gives no answer to the questions posed at the end of the above section.

\section{Introductory CS Misconceptions and Web Technologies: Comparison of two Studies}

The above sections introduced the problem of misconceptions and mental schemes' presence and reported some of the strategies, often based on IT use, researchers and teachers use to help students in overcoming their difficulties. Now the description of two experiences follows: the former one concerns the teaching of 
Web Technologies and Sciences Epistemologies

Computer Programming introductory concepts in a traditional context, the latter one refers to the introduction of Web technologies in teaching work.

\section{When All Seems to Work Wrong}

The first experience concerns a class of an Italian Technical High school (16-17 age students) involved in computer programming paradigms teaching-learning during school years 2000-2001 and 2001-2002 and can be separated in two phases: the former one based on computer programming teaching and on the analysis of the students' results (school year 2000-2001), the latter one related to a specific test the students were submitted to (school year 2001-2002).

Teaching work in that class was planned taking in the right count the results of previous studies the author held on Computer Programming misconceptions (Cartelli 1994, Cartelli 1997) and didn't require specific IT strategies or applications (the PCs were used only into the laboratories to write and run the programs the students designed in Pascal, $\mathrm{C}$ and Prolog). Teaching was based on constructivistic principles that is: participated lessons, introduction of disciplinary themes starting from concrete problems, discussion of the hypotheses the students could propose for the solution of a problem by each one of them within the class, etc. The result of this work agreed with previous researches because at the end of the school year only 6 students $(24 \%)$ still manifested some wrong ideas.

At the beginning of the following school year (2001-2002) after a short recovery and widening action the same students confirmed their good results. But an event very important for our study occurred during this last year: the selections for Computer Science Olympiads, when all the students of that class answered to the questions of a specific test.

We will limit in what follows to the analysis of the only questions of the test concerning computer programming (i.e. variables definition and use, logic conditions within an if statement, cyclic structures, subprograms and functions). If it's true that the various items contained answers strongly misleading it has to be noted that only three/five students $(15 / 20 \%)$ selected the right answers. This result is not surprising because of the great amount of analogous examples in previous researches; as an example is reported here the case of the answers university students gave to the following question after having attended many Physics courses: what forces are acting on the five balls a player is throwing up, when they are at the same height with different speeds? A lot of them (75\%) asserted the forces were all different also if on the various balls is acting only gravity.

The above results seem to propose together with the need for a deep analysis of misconceptions and mental schemes a new set of situations to analyse: are there problems or questions influencing the use the students can do of their scientific concepts (when correctly acquired) and inducing them to show misconceptions and mental schemes? What can be done to avoid these new problems and what influence they can have on everyday teaching?

\section{Teaching on the Web}

In this section the results of two experiences involving the use of the Web to teach CS introductory concepts are compared.

The first experience relates to the distance learning project Icaro of Sicily Italian Regional administration devoted to the rehabilitation of young people that had problems with justice (Cartelli, 2001). Main traits of the project were: 1) a module on computer structure and use (focusing on the Internet and its services), 2) tutors supporting students' work in presence and on line, 3) two different kinds of users: teachers in the schools where the boys and girls to be rehabilitated were studying and educators within the structures giving hospitality to the same young people. The test proposed at the end of the introductory CS module (20 
questions concerning hardware and software of a PC, Windows operating system and the Internet) had the following results:

- the teachers answered correctly $73 \%$ of the items (32\% exact answers more than in the input test) and made mistakes in $27 \%$ of them (as in the input test)

- the educators answered correctly $76 \%$ of the items (57\% exact answers more than in the input test) and made mistakes in $24 \%$ of them (as in the input test)

The experience to be compared with the above one concerns the use of an on line system to be used as an e-learning platform supporting university teaching. Main traits of this system were: 1) to give to the students of a first year university course the basic knowledge of the structure and functions of a PC (including the use of the Internet); 2) to be strongly based on the use of images (graphics and photos) and animations (animated gifs); 3) systematically adopt self-assessment tests for each topic (so that students could verify their learning level and when in a mistake could see where they were wrong and go back to the corresponding pages of the course); 4) to let the students use a synchronous-asynchronous communication system (very similar to a Web Chat) to exchange messages with the teacher or among themselves; 5 ) to be interfaced with a Database so that every operation a student did (from seeing a page to sending or receiving a message) was stored within the database (Cartelli, 2002). The above site was ready and running during academic year 2000/2001 when the courses the author was involved in were almost at the end; notwithstanding this 31 students of the Faculty of Humanities (attending the course of Technology for education and having already attended an introductory CS course) accepted to use the site as a complement to their course. At the end of this experience (during which two on line meetings outside the lessons times were scheduled) the data stored within the database showed what follows: a) 18 students (58\%) read only the self-assessment tests in the site (often answering each question more times - at least until their answers were correct); b) 10 students (32\%) started from the self-assessment tests and read only a part of the course Web pages (mostly the ones with the arguments concerning their wrong answers); c) only 3 students $(10 \%)$ read nearly all the course pages before answering the questions in the self-assessment tests. Surprisingly the Chat was not used as one could expect: only five students were on-line in the two stated periods and two further students joined them in other periods (to discuss among themselves). What's more, they only put on the Chat cheering and greeting messages; in other words they never used the Chat to analyse problems settled during the lessons or to ask help to the author or to other students.

Together with the above remarks are very important for what follows the answers the students gave to the written test at the end of the period of use of the site. The test submitted to the students was very similar to the one adopted in the above experience and $72 \%$ of the answers they gave was correct. Some questions and particularly the ones concerning the meaning of Operating System, the function of the screen pointer and the meaning of the word browsing need further remarks:

- $74 \%$ of the students thought of an O.S. "it's an integrated system (not better specified) to put the PC at work" more than "it's the set of programs administering the PC resources";

- $\quad 77 \%$ of them looked at the screen pointer as "the instrument to move objects on the desktop" more than "one of the elements of the human-computer interaction";

- $55 \%$ of them were persuaded that browsing the Web was synonymous of "connecting to the Internet" more than "getting pages from the Web with a program".

It has to be noted there is small or no correlation at all among the students approach to the course and the answers they gave to the written test (i.e. the students who read all the pages before using the self assessment tests gave the wrong answers just as the students who used only the self assessment tests). Just in the same way it is interesting to compare the answers of the students with the same answers the teachers and 
Web Technologies and Sciences Epistemologies

the educators gave to the test at the end of their course. In table 1 the percentages of the wrong answers of the different samples of individuals are reported.

\begin{tabular}{|l|c|c|c|}
\hline Items analysed & Teachers & Educators & Students \\
\hline Operating System & $48 \%$ & $50 \%$ & $74 \%$ \\
Screen pointer & $48 \%$ & $56 \%$ & $77 \%$ \\
Browsing & $20 \%$ & $22 \%$ & $55 \%$ \\
\hline
\end{tabular}

The first comment naturally arising from the data reported in the table concerns the relevant role the on line and presence tutors played in the learning process ( $25 \%$ of correct answers more than in the students

Table 1: Teachers, Educators and Students wrong answers case). Furthermore if it is true the above results are partial as they involve a little sample of students and there is the need for more and deep experiments, some questions arise:

a. The site structure revealed important in helping the students to overcome part of their difficulties but didn't solve all the problems they had and, once more, ambiguous situation were responsible for the students' wrong answers.

b. How much distance learning environments can be used in everyday teaching work with school students? It is perhaps too early to say but an experiment the author is carrying on with the students of an Italian technical high school shows it's very difficult to persuade them to currently use the Internet for their work.

\section{Conclusions}

The amount of themes the paper faces up imposes a great attention in the definition of scenarios and hypotheses concerning teaching-learning processes. A remark naturally emerges from a careful reading of the above sections: no question receives a definitive answer from the results of the researches carried out by the author and any other scholar.

If the natural consequence of the above assertion is that there is the need for further studies it is important to define the field of interest for these studies.

In the author opinion the real questions marking future studies (emerging from a paraphrase of the questions settled in the different sections) will be due to:

a) deep analysis on human knowledge and particularly: what differences are there between natural and scientific knowledge? How human mind builds scientific knowledge?

b) what disciplines have to be involved in the analysis of teaching-learning processes? what strategies and techniques have to be adopted?

c) what role the teachers have to play in educational processes?

With respect to the first set of questions concerning knowledge definition and construction the studies on wrong ideas have the great merit they open once again a problem that seemed definitely solved. If it is true, in fact, that further studies have to be carried out to get more information, we are not starting from the beginning: the Ausubel's hypotheses of knowledge units joining among themselves to build new knowledge (also taking in count the objections of West) depict a static situation that has no confirmation in the results of the researches reported in the above sections. It is undoubted there is a natural knowledge emerging from human interaction with the environment and leading to the construction of mental schemes that work pretty well in everyday life. More complex is the situation with respect to scientific knowledge and its interaction with natural knowledge: the hypothesis assigning to scientific knowledge the meaning 
of a deep natural knowledge doesn't find confirmation in the results of the researches (why people use natural mental schemes when they have scientific ones?). In the author opinion a model more suitable to interpret misconceptions and mental schemes presence with respect to the above one can be hypothesised: scientific knowledge is the result of the superposition of scientific paradigms to natural mental schemes; in this model scientific paradigms never substitute natural ones but intervene in phenomena interpretation if they are strongly impressed in individual practice (they become a sort of glasses for seeing reality from a particular point of view).

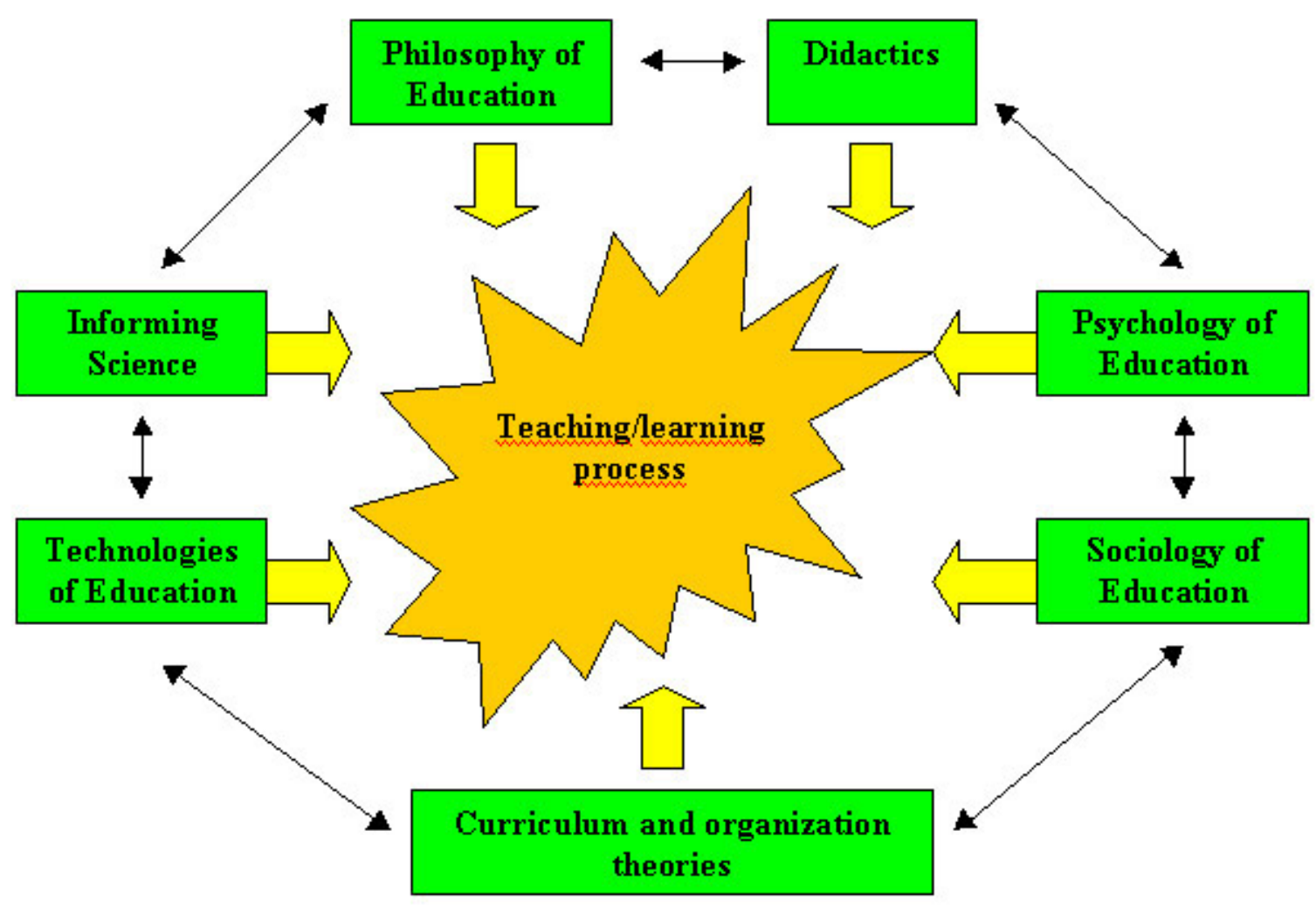

Fig. 1 - Disciplines involved in the study of teaching-learning phenomenon

Another question suddenly arises: are there diagnostic instruments to find a confirmation for the above hypothesis? Till now the inquiry techniques have been the ones adopted by Psychology and Sociology: tests and interviews (Piaget used for his studies clinic interviews). Main traits of the above techniques are: a) the tests intervene at the begin and at the end of the process to analyse to determine what changes a given experiment induces in individuals' mental schemes; b) the interview as a process of interaction between two individuals (i.e. the researcher and the student) modifies the mental frames of the subject to be observed. In the author opinion the use of an information system like the one he adopted in the above section to build an e-learning environment can be a useful inquiry instrument. It operates in fact in a transparent way (the user interact with it like a normal Web site but every operation he/she does is stored) and can give at any instant a snapshot of user interaction with the system (quantitatively: number of pages visited, amount of answers to the tests etc. and qualitatively: what pages are visited more often, what answers are selected or written etc.).

As a consequence a further question needs an answer: what disciplines have to be involved in teaching/learning processes analysis? Till now the hypotheses coming from most important scholars assign a leading role to philosophy of education, didactics, psychology of learning, sociology of learning, theories of curriculum and technologies of education. In the author opinion Informing Science too has a relevant role in the analysis of teaching and learning processes. This proposal has its root in the following reasons: 
Web Technologies and Sciences Epistemologies

a) the use the author made of the above information system to analyse the students apprenticeship styles by means of their interaction with it; b) Cohen's definitions concerning Informing Science (Cohen, 1999): "The fields that comprise the discipline of Informing Science provide their clientele with information in a form, format and schedule that maximises its effectiveness" and "The Informing Science Framework has three components: the informing environment, the delivery system and the task-completion system". Figure 1 depicts the above situation.

The arrows joining the disciplines in Fig. 1 have to be interpreted as communication channels leading all together to a structure very similar to a token-ring network within which information flow from a discipline to another.

At last remains the question: what role the teachers have to play in teaching-learning processes? The author agrees with many recent studies falling in Action-Research tradition and attributing new and more important functions to teachers: they have to become didactic researchers in their everyday work, that is while collecting data from the working environment they have to interact with it and modify it (i.e. the feed-back from students' behaviour increases the teacher knowledge on the learning processes and makes easier the finding of the elements useful for a scientifically correct knowledge; it is then possible for the teacher to intervene in the construction of a meaningful learning in students' minds).

\section{Further Studies}

The results of the author researches had a first important effect: they induced a revision for the Web site structure. In future release of the system, in fact, one or more concrete situations for each topic will be proposed to the students for an analysis. These problem-solving situations will be slightly different from the tests: the starting point for the problem analysis will be the description of the situation with all its boundary terms, it will be followed by some hypotheses to select (like closed answers) and a free text area students will use to write a solution. Depending on the reported situations, the selection of an hypothesis will lead to another situation to analyse and so forth or to an ending message and at last at the home page (as an example one can consider the main traits of a problem that will be proposed for the first topic: you have to buy a PC or a notebook with a given budget, here are their features ... and their prices ... what are the elements you will analyse to make a choice? ...). It's important to note there will be no assessment for the students' answers and ambiguous situations will be planned and introduced systematically within the problem solving to enhance differences among possible natural reasoning and correct discipline ideas. At last an analysis of the correct situation will be proposed and the reasons for its correctness will be reported.

The next step in the author's research will also see the introduction of the Web site in school and academic teaching plans together with the synchronisation of the lessons and of the lectures with the students' access to the Web Chat and with the problem solving sections.

The intervention of presence tutor will be planned to give a support to students work.

Other experiences the author will undertake concern the choice of the instruments to adopt in the Web production: software Open Source has been adopted until now (Linux as O.S., Apache as Web server, Postgresql as RDBMS, PHP3 as front end system) and in the future this choice will be confirmed, but JSP and XML will probably contribute in modifying the site structure.

\section{References}

Ausubel D. P., (1990). Educazione e processi cognitivi, Franco Angeli, Milan (Italy).

Calvani A., Rotta M., (1999). Comunicazione ed apprendimento in Internet, didattica costruttivistica in rete, Erickson, Trento (Italy). 
Calvani A., Rotta M., (2000). Fare formazione in Internet, manuale di didattica on-line, Erickson, Trento (Italy).

Cartelli A., (1985). Mental Representation Frames in Middle School Children: Force and motion, unpublished thesis for the Special School in Physics of the University "La Sapienza" (two years post doctoral school), Rome, 22/03/1985.

Cartelli A., (1994). Misconcetti e scemi alternativi in Informatica, in Proceedings of "DIDAMATICA 1994 - Informatica per la didattica", scientific works section, (a cura di A. Andronico, G. Casadei, G. Sacerdoti), Il Ponte Vecchio, Cesena - FO (Italy), pp. 87-102

Cartelli A., (1997). Alcune indicazioni di carattere metodologico nell'insegnamento dei paradigmi di programmazione, in Proceedings of "DIDAMATICA 1997 - Informatica per la didattica", scientific works section, (a cura di A. Andronico, B. Piochi, G. Sacerdoti), Tipografia senese, Siena (Italy), pp. 133-140

Cartelli A., (2001). Web Tech and new Paradigms in Cognitive Sciences, in Proceedings of IS 2001 Conference "Challenges to Informing Clients: A Transdisciplinary Approach", Cracow (PL), pp. 122-128. Available on line at: http://ecommerce.lebow.drexel.edu/el1/pdt/CartelliEBKWebTe.pdt

Cartelli A., (2002). Didattica, tecnologie Web e apprendimento: analisi e prospettive, accepted for publication in Proceedings of "DIDAMATICA 2002 - Informatica per la didattica", scientific works section, Naples (Italy)

Cartelli A., Ruggiero S., (2000). Misconcetti e Web: un sito dedicato all'autovalutazione ed all'autoapprendimento, in Proceedings of "DIDAMATICA 2000 - Informatica per la didattica", scientific works section, (a cura di A. Andronico, G. Casadei, G. Sacerdoti), Il Ponte Vecchio, Cesena - FO (Italy), pp. 123-133

Cartelli A., Ruggiero S., (2001). Un'esperienza di formazione a distanza: il progetto Icaro, in Proceedings of "DIDAMATICA 2001 - Informatica per la didattica", scientific works section, (a cura di A. Andronico, A. M. Fanelli, G. Piscitelli, T. Roselli), Giuseppe Laterza, Bari (Italy), pp. 121-129

Casey C., (1996). Incorporating cognitive apprenticeship in multimedia, in Educational Technology Research and Development, 44 (1) 71-84.

Cohen E. (1999). Reconceptualizing Information Systems as a Field of The Transdiscipline Informing Science: From Ugly Ducking to Swan, Journal of Computing and Information Technology. 7 (3), 213-219

Driver R., Erickson G., (1983). Theories in action: some theoretical and empirical issues in the study of students' conceptual frameworks in science, in Studies in Sc. Educ., 10, 37

Galliani L., Costa R., Amplatz C., Varisco B. M., (1999). Le tecnologie didattiche, Pensa, Lecce (Italy).

Greening T., (2000). Computer Science Education in $21^{\text {st }}$ Century, Springer Verlag, New York.

Johnson R. T., Johnson D. W., Stanne M. B., (1985). Effects of cooperative, competitive, and individualistic goal structures on computer assisted instruction in Journal of Educational Psychology, 77 (6), 669-677.

Jonassen D. H., (1994). Learning with media: Restructuring the debate, in Educational Technology Research and Development, 42 (2), 31-39.

Jonassen D. H., (1994). Thinking technology: Toward a constructivistic design model, in Educational Technology, April, 34-37

Lemut E., du Boulay B., Dettori G., (1993). Cognitive models and Intelligent Environments for Learning Programming, NATO ASI Series v. 111, Springer Verlag, Berlin.

Lévy P., (1996). L'intelligenza collettiva. Per un'antropologia del cyberspazio, Feltrinelli, Milan (Italy).

Mc Lellan H., (1996). Being digital, Implications for education, in Educational Technology, November/ /December, 5-20.

MLRG (Meaningful Learning Research Group) Web site reports the titles of the papers presented at four different international meetings on misconceptions and meaningful learning: 1) Proceedings of the misconceptions in Science and Mathematics,

2) Second Misconceptions Proceedings, 3) Third Misconceptions Proceedings, 4) Proceedings of "From misconceptions to constructed understanding". The Web site is available on line on March $15^{\text {th }} 2002$ at tttp://Www.mlrg.org/

Piaget J., (1973). La costruzione del reale nel bambino, La Nuova Italia, Florence (Italy).

Piaget J., Inhelder B., (1950). Les notions de mouvemet et de vitesse chez l'enfant, PUF, Paris.

Rheingold H. (1994), Comunità virtuali. Parlare, incontrarsi, vivere nel cyberspazio, (1994), Sperling \& Kupfer, Milan (Italy).

Santelli Beccegato L., (1998). La didattica un sapere che viene da lontano, in Studium Educationis "Lineamenti di didattica", IV, 607-611. 
Web Technologies and Sciences Epistemologies

Skinner B. F., Holland J. G., (1960). The use of teaching machines in college instruction, in Teaching machines and programmed learning (A. A. Lumsdaine and R. Glaser, Eds.). Washington, D.C.: Nat. Educ. Ass., 159-172.

Taylor R., (1980). The Computer in the School: Tutor, Tool, Tutee, Teachers College Press, New York.

Varisco B. M., (2002). Costruttivismo socio-culturale: genesi filosofiche, sviluppi psico-pedagogici, applicazioni didattiche, Carocci, Rome (Italy).

Vicentini M., Mayer M., (1998). Didattica della fisica, La Nuova Italia, Florence (Italy).

West L. H., Fensham P. J., (1974). Prior knowledge and the learning of science; a review of Ausubel's theory of this process, in Studies in Sc. Educ., I, 61-81.

\section{Biography}

Antonio Cartelli is a teacher of CS (i.e. European I.T.) in an Italian Technical High School and has a yearly contract for teaching Educational Technologies at the Faculty of Humanities in the University of Cassino - Italy. A. Cartelli is also administering the Network Services in the same Faculty and has authored more than 15 papers on the subjects of Web technologies and conceptualisation, misconceptions and mental schemes in different disciplines. 